\title{
Educação ambiental em escolas particulares de Goiânia: do diagnóstico a proposições sobre formação de professores
}

\author{
Agustina Rosa Echeverría ${ }^{1}$ \\ Fabiana Melo Rodrigues ${ }^{2}$ \\ Kleber Rezende Silva ${ }^{3}$
}

Resumo: 0 presente artigo apresenta os resultados de uma investigação desenvolvida em escolas particulares de Ensino Médio da cidade de Goiânia. Procurou-se identificar as atividades de Educação Ambiental realizadas pelos professores dessas escolas. Os dados analisados foram construídos a partir de questionários e entrevistas aplicados aos professores. A análise mostrou que a maioria desses professores teve uma formação inicial voltada prioritariamente para a abordagem dos aspectos físico-naturais da questão ambiental, o que faz com que as atividades por eles desenvolvidas, que são realizadas de forma esporádica, estejam voltadas para esses aspectos. Propõe-se que, para a construção de uma Educação Ambiental crítica, os cursos de formação de professores têm de abordar a complexidade das questões ambientais de forma curricular, na formação inicial e nos cursos de pós-graduação. Por último, defende-se a participação da Universidade em Projetos Ambientais que envolvam a comunidade em geral.

Palavras-chave: Educação Ambiental, Escolas Particulares.

Abstract: This article presents the results of a research carried out in private secondary schools in the city of Goiânia. The Environmental Educational activities implemented by the teachers of such schools were examined based on the data drawn from questionnaires and interviews. The analysis of this set of data shows that the majority of those teachers received a basic education focused on the physical and natural aspects of the environmental issue, what makes the activities sporadically done by these teachers to be oriented to these aspects. In conclusion, in order to provide the construction of a critical Environmental Education, we propose that teacher education courses should approach environmental issues in a curricular way to guarantee their discussion at the initial stages of teachers' education. The same should be applied to the

1 Professora do Instituto de Química da Universidade Federal de Goiás; Sub-Coordenadora do Mestrado em Educação em Ciências e Matemática, Professora do Doutorado em Ciências Ambientais. Contatos: Rua 15, 220. Ap.500. Ed. Chaillot. Setor O este. Goiânia. Goiás CEP 74140 ou agustina@quimica.ufg.br

2 Licenciada e mestre em Química pela UFG

3 Funcionário da Secretaria de Educação do Estado de Goiás - Área Administrativa kleberquim@yahoo.com.br 
continuous education and postgraduate courses. Finally, we defend the participation of the university in projects involving the community.

Keywords: Environmental Education, Private Schools.

\section{Introdução}

A questão ambiental tem sido amplamente discutida nos seus mais diversos aspectos, uma vez que alcança diferentes áreas da vida humana. Os problemas ambientais, considerados aqui como resultado da relação entre sociedade e ambiente, indicam a existência de duas relações interdependentes: dos seres humanos entre si (meio social) e dos seres humanos com o ambiente (meio físico-natural) (Q UINTAS, 2004). Esses problemas têm como origem não só as ações antrópicas sobre 0 ambiente, mas, também, os fenômenos decorrentes do próprio meio físico natural, desde a época em que o ser humano ainda não existia.

No entanto, a partir do século XIX, a concepção e atitude antropocêntrica e pragmático-utilitarista sobre 0 ambiente começa a ser contestada. A termodinâmica e 0 evolucionismo reintroduzem a história e a irregularidade no relógio universal newtoniano. 0 absolutismo e a certeza são bombardeados pela relatividade e pelo princípio da incerteza (SOFFIATI, 2002). Uma nova imagem de natureza se mostra diante de nossos olhos, uma natureza permeada por comportamentos complexos, exigindo para a crise ambiental da atualidade uma nova racionalidade e consequentemente novas metodologias capazes de orientar um processo de reconstrução do saber que permita realizar uma análise integrada da realidade (LEFF, 2001).

0 que se almeja é redimensionar as relações entre as sociedades humanas e 0 ambiente, procurando consentir um contrato de modo que deixem de ser antagônicas. Novas formas de exercício da cidadania e a formação de um novo educador que atue a partir de novas premissas são essenciais para a consolidação do paradigma organicista contemporâneo.

A emergência da crise ambiental como uma preocupação específica da Educação foi marcada por uma "ecologização das 
sociedades", ou seja, o ambiente deixou de ser um assunto apenas dos defensores da natureza e se tornou um assunto da sociedade em geral. Seus primeiros enunciados datam de 1945, quando ocorreram as explosões das bombas atômicas sobre as populações civis de Hiroshima e Nagasaki. De modo sarcástico, a explosão das bombas trouxe à tona os primeiros sinais de preocupação com o ambiente (G RÜN, 1996).

0 debate ambiental, mais do que um modismo em voga, nos alerta para os diferentes modos pelos quais a sociedade humana se relaciona com os meios construído e natural, desde os tempos mais remotos. No caso particular da natureza, não há como ignorar a necessidade que temos dela para nossa existência e sobrevivência. Ao mesmo tempo que a natureza nos dá suporte de existência biológica e social, é sumidouro dos mais diferentes tipos de rejeitos e dejetos produzidos nas nossas atividades.

O desafio para a construção de uma cidadania consistente encontra-se na capacidade de instituir práticas democráticas cotidianas, de favorecer o progresso de uma escola capaz de levar o aluno a refletir criticamente sobre seu ambiente de vida e de consolidar uma cultura da cidadania, nos planos local, regional e internacional, articulada aos processos de transformação sistêmica (LO UREIRO, 2002).

Entendemos que um documento que sinaliza de forma lúcida uma educação ambiental para o efetivo exercício da cidadania é a Carta de Belgrado. Nela se colocam como indispensáveis a conscientização, o conhecimento, o comportamento, a competência, a capacidade de avaliação e a participação como princípios a serem exercidos na busca da erradicação da pobreza, da fome, do analfabetismo, da poluição e da dominação e exploração humana para a construção de uma nova ética global. (D IAS, 1992).

Nesse sentido, a Educação Ambiental não pode ser pensada simplesmente como transmissão de conteúdos, visto que isso compromete a conquista da consciência de uma rede complexa de aspectos políticos, econômicos, culturais e científicos. Uma ação educativa ambientalista, sem as devidas orientações políticas e teóricas, perde seu efeito transformador e não expressa aumento qualitativo da consciência e do exercício da cidadania ecológica, diante do ápice da 
degradação da qualidade de vida e do ambiente, por mais ricas que sejam suas propostas metodológicas e práticas (LO UREIRO, 2002).

É essencial reconhecer que a educação tem se mostrado incapaz de conseguir êxito na construção de uma visão crítica. Isso acontece devido aos inúmeros problemas que ela enfrenta, tais como: a falta de investimentos na estrutura física das escolas, na formação do professor, nos diversos aspectos que garantem a aprendizagem dos alunos (alimentação, saúde, bibliotecas, entre outros). Compreendendo o papel do professor como determinante nesse processo, defendemos uma formação inicial que efetivamente 0 capacite para sua profissão. Para isso, torna-se necessária uma reavaliação de cursos parcelados ou a distância que, na maioria das vezes, fragilizam essa formação (ECHEVERRÍA; BENITE; SOARES, 2007). Portanto, há uma necessidade urgente de se considerar a importância do professor na formação de um ser humano reflexivo, apto a entender a complexidade da vida.

Nesse contexto, a Educação Ambiental vem ganhando espaços cada vez maiores nos sistemas de ensino. Há que se destacar a publicação dos PCN (Parâmetros Curriculares Nacionais) para o ensino fundamental em 1997, os quais trazem o meio ambiente como tema transversal (BRASIL, 1997), e também a promulgação da Lei 9.795/ 99, que estabelece a PNEA (Política Nacional de Educação Ambiental), colocando-a como uma obrigação legal e de responsabilidade de todos os setores da sociedade, da educação formal e informal (BRASIL, 1999).

Várias pesquisas têm discutido a Educação Ambiental no ensino formal. Melo (2001) tematiza demandas referentes à emergência e ao lócus da dimensão ambiental da educação, ressaltando a contribuição das novas tecnologias de informação e de comunicação no tocante ao desafio de inserir e integrar a Educação Ambiental na agenda educacional, de forma a estabelecer novos valores que ajudem os indivíduos a enfrentar novas realidades sociais, ambientais e de desenvolvimento, em rápida transformação. Velasco (2002) destaca alguns tópicos da PNEA, esclarecendo certos conceitos em Educação Ambiental e suas esferas de ação, a fim de contribuir tanto na tarefa de 
zelar pelo seu cumprimento quanto na de propiciar alterações que venham a suprir carências da mesma. Andrade (2000) discute 0 processo de implementação da Educação Ambiental nas escolas reconhecendo-a como uma unidade capaz de reduzir os impactos ao ambiente e também de buscar mudanças curriculares que possam não só diminuir a influência da cultura predatória do meio ambiente, mas, talvez, invertê-la.

Como Freire (2001) afirma, mudar é difícil, mas é possível. A educação não pode tudo, mas pode muita coisa. A realidade pode e deve ser mudada, transformada. Como Porto-Gonçalves, entendemos que:

Com freqüência ouvimos dizer que sempre houve ricos e pobres ou opressores e oprimidos e que, portanto, isso é natural - logo, imutável. Isso não passa de uma boa maneira de se deixar tudo como está. Pretende-se congelar a história, a sociedade e a cultura, enfim, manter o status qua (...) Portanto, devemos ter muito cuidado quando nos tentam convencer de que isso ou aquilo é natural pois, quase sempre, o que se está querendo exatamente escamotear é aquilo que é da natureza da história, da sociedade e da cultura, isto é, a tensão e 0 conflito de onde 0 novo, 0 diferente, pode brotar (PORTOGONÇALVES, 2004b, p. 44).

Dessa maneira, a educação tem um grande potencial no que diz respeito à busca de novas formas de relacionamento entre 0 ser humano e 0 ambiente. 0 processo educativo é uma construção social repleta de subjetividade, de escolhas valorativas e de vontades políticas, com a especial particularidade de reprodução dentro da sociedade. Ela pode tanto transformar o mundo quanto estar a serviço da acomodação dos seres humanos à realidade tida como intocável (FREIRE, 1996; LIMA, 2002).

O campo educacional tem se caracterizado nos últimos vinte anos por um modelo pragmático voltado preferencialmente para atender as demandas do mercado, que por sua vez refletem a nova reacomodação do mundo do capital. Nesse contexto, Sterling (2001) 
chama a atenção para dois possíveis tipos de educação, que ele denomina de $1^{\underline{a}}$ e $2^{\underline{a}}$ ordens. Os processos de $1^{\underline{a}}$ ordem propõem uma mudança que sirva para a adaptação às novas realidades do mercado; já os de $2^{\text {a }}$ ordem pressupõem uma educação voltada para uma intervenção qualitativa na realidade na perspectiva da mudança a partir da formação de sujeitos críticos e autocríticos.

A Educação Ambiental crítica, em sua vertente mais atual, que busca a articulação das ciências e da produção de conhecimentos para a construção de uma nova racionalidade ambiental, estaria relacionada aos processos de $2^{\underline{a}}$ ordem. É a racionalidade ambiental que implica uma nova teoria de produção, novos instrumentos de avaliação e, ainda, incorpora novos valores que dão sentido aos processos emancipatórios, redefinem a qualidade de vida das pessoas e o significado da existência humana (SACHS, 2002).

É importante destacar que muitas vezes a Educação Ambiental tem sido realizada com base em ideias equivocadas, que trazem consequências graves para a pretensa aspiração de estabelecer uma educação que mude valores. Recorrentemente, encontram-se profissionais da educação confundindo Educação Ambiental com ensino de ecologia. A Educação Ambiental é muito mais abrangente que 0 estudo da ecologia, embora não dispense este conteúdo. A complexidade dos problemas ambientais tem gerado conflitos que dificultam a sua resolução. A contaminação dos rios por mercúrio é um exemplo dessa complexidade. Atividades geralmente ilegais (garimpos) contaminam rios e peixes, que por sua vez são a principal fonte de alimentação de populações ribeirinhas. Uma Educação Ambiental que contribua para uma mudança da realidade necessita abordar todas as variáveis e os conflitos existentes em situações como essa.

Dessa forma, a Educação Ambiental que propomos requer a construção de novos objetos interdisciplinares de estudo por meio da problematização dos paradigmas dominantes, da formação dos docentes, da incorporação do saber ambiental emergente em novos programas curriculares. 


\section{Sobre a nossa pesquisa}

Considerando que o Brasil é um país com profundas desigualdades sociais onde as parcelas minoritárias da população são responsáveis pela tomada de decisões que afetam a maioria e que essas parcelas minoritárias têm sua educação formal realizada em estabelecimentos particulares de ensino, foi de nosso interesse elucidar como a Educação A mbiental é abordada nessas escolas.

De acordo com o IBGE (2001), a cidade de Goiânia possuía por volta de 770 estabelecimentos de ensino, compreendidos entre escolas de educação infantil e ensino básico. Com relação às escolas de ensino médio, os dados mostram a existência de 147 estabelecimentos, dos quais 2 são federais, 89 são estaduais e 56 são particulares. Como se procurava conhecer a realidade das escolas particulares, os dados do IBGE foram cruzados com os fornecidos pelo SINEPE-GO (Sindicato dos Estabelecimentos Particulares de Ensino do Estado de Goiás) e pelo SEPE (Sindicato dos Estabelecimentos Particulares de Ensino de Goiânia), o que resultou em um número de 55 escolas. Através de contatos telefônicos, procurou-se saber em quais delas eram desenvolvidos trabalhos em Educação Ambiental. Dezenove escolas responderam afirmativamente, motivo pelo qual foram escolhidas para 0 estudo. Entre elas, 12 estão situadas em bairros considerados de classe alta, 6 em bairros de poder aquisitivo médio e 1 em bairro de baixo poder aquisitivo. Q uanto ao tamanho, 11 são de pequeno porte (80 a 150 alunos), 4 de médio porte (200 a 350 alunos) e 4 de grande porte (400 a 1.100 alunos). Sete são confessionais e 12, laicas. Essas escolas representam por volta de 34\% das escolas particulares de ensino médio de Goiânia e aproximadamente $41 \%$ dos alunos matriculados nessas instituições.

Escolhidas as escolas que realizavam atividades relacionadas à temática ambiental, procuraram-se os professores responsáveis por essas atividades. Identificaram-se 40 professores, aos quais foi aplicado 0 primeiro instrumento de pesquisa: 0 questionário semiaberto. 0 mesmo foi escolhido por oferecer vantagens, como a possibilidade de obtenção rápida de um maior número de informações. 0 questionário constou de 23 perguntas com as quais se pretendia identificar o perfil 
socioeconômico-cultural desses professores, as atividades por eles desenvolvidas - seja por meio de trabalhos realizados isoladamente, seja por meio de projetos da escola - e suas concepções sobre a problemática ambiental. Dessa forma, nossa amostra compreende professores de G eografia, História, Matemática, Biologia e Q uímica.

Dos 40 questionários entregues, foram devolvidos 28, que se constituíram em nosso objeto de estudo. A partir da leitura desses questionários, construíram-se as categorias de análise. Ao mesmo tempo, perceberam-se algumas desvantagens desse instrumento, quais sejam, respostas incompletas ou perguntas não respondidas. D essa forma, decidiu-se pelo segundo instrumento; a entrevista semiestruturada (LÜDKE; ANDRÉ, 1986). Foram entrevistados 9 professores cujos questionários apresentaram esses problemas. Os entrevistados responderam às perguntas de posse dos seus próprios questionários, o que possibilitou que as respostas fossem incluídas nas mesmas categorias de análise. As entrevistas, gravadas em áudio e transcritas na sua totalidade, foram realizadas no período de dezembro de 2003 a maio de 2004.

\section{Resultados e Discussão}

Em relação aos dados socioeconômico-culturais que caracterizaram os professores, destacamos a renda familiar. D os 28 professores pesquisados, 14 declararam receber acima de 10 salários mínimos, 4, até 10 salários mínimos, 5 , até 8 salários mínimos, 3, até 5 salários e 2 não responderam. Esses resultados são significativamente diferentes dos obtidos por Fonseca (2001), que constatou que 45\% dos professores da rede pública municipal de ensino possuem renda de até 5 salários mínimos. Assim, constatamos que os professores da nossa pesquisa possuem rendimentos bem acima daqueles da rede pública de ensino, fato que irá refletir nas atividades culturais das quais participam, tais como: congressos, conferências e simpósios (71\%), cinema (57\%), teatro (46\%), musicais, corais e orquestras (50\%). Isso nos leva a inferir que essas atividades culturais e acadêmicas auxiliam na formação 
continuada desses professores, o que pode influenciar o tratamento dos temas abordados em sala de aula, entre eles a Educação Ambiental.

Do universo de professores pesquisados, 14 lecionam a disciplina Biologia, 10 lecionam G eografia, 2, Q uímica, 1, Matemática e 1, História. Esses dados confirmam nossas expectativas de serem professores de Biologia a maioria a desenvolver atividades relacionadas à questão ambiental. Diversas pesquisas (REIG OTA, 2007) têm mostrado que são biólogos a maioria dos profissionais que lidam com essa temática. Contudo, a preocupação com a questão ambiental tem envolvido profissionais de diversas áreas do conhecimento. Reigota (2007) salienta que, embora a Biologia tenha importantes contribuições a dar à Educação Ambiental, ela não está mais autorizada que a História, o Português, a Química, a Física, entre outras, a contribuir para a construção de uma Educação Ambiental crítica. D e acordo com Penteado (1994), as questões ambientais necessitam, de um lado, ser analisadas pelas Ciências Humanas, que nos aproximam da compreensão desse aspecto, e, de outro, pelas Ciências Naturais, com seus conhecimentos específicos, por professores capazes de uma abordagem socioambiental.

No que se refere à formação, identificamos que, na ocasião, 2 eram graduandos, 10, graduados, 10, especialistas, 1 cursava 0 mestrado, 3 já eram mestres e 2 estavam cursando o doutorado. Em princípio, podemos concluir que os professores, na sua maioria, estão qualificados para abordar a problemática ambiental em sala de aula.

Sobre as atividades desenvolvidas, verificamos que as práticas dos professores são, na maioria dos casos, influenciadas pela área de formação. Assim, os professores formados em Biologia relataram atividades voltadas a temas como: preservação de rios, da fauna e da flora, entre outros. Os geógrafos desenvolvem atividades relacionadas com assoreamento, erosão, desmatamento, gestão ambiental, geomorfologia. Os químicos disseram ter abordado temas como 0 tratamento de água.

Ainda sobre a formação, perguntava-se se na grade curricular do curso de graduação existiram disciplinas relacionadas às questões ambientais e à Educação Ambiental. A maioria dos professores (75\%) respondeu que sim, que teve na formação inicial disciplinas que 
discutiam esses assuntos. Entretanto, as disciplinas citadas (Ecologia, Biogeografia, Zoologia) mostram que nessa formação os temas ambientais podem ter sido abordados principalmente nos aspectos físico-naturais, o que restringiria a abordagem mais crítica da complexidade ambiental.

Analisando outros estudos, verificamos que Barreto, G uimarães e Silva (2003) buscaram saber se nas disciplinas do curso de Licenciatura em Pedagogia da UFPA discutem-se as questões ambientais e verificaram que apenas 4 disciplinas fazem referência à Educação Ambiental; 40 disciplinas não fazem qualquer referência. Costa e Freitas (2003) analisaram o grau de inserção da temática ambiental no currículo do curso de Licenciatura em Pedagogia na UFSCar e mostraram que a proposta de reformulação curricular desse curso favorece essa inserção, assim como a incorporação dos elementos da complexidade. Baía Júnior e Guimarães (2003) analisaram os currículos de Ciências Biológicas de 19 IFES a fim de verificar a existência de disciplinas com conteúdos ambientais e constataram que, do total de disciplinas que compõem os currículos desses cursos, apenas $1 \%$ apresenta conteúdos ambientais. Contudo, a pesquisa mostra que algumas Universidades Federais já possuem, inseridas em seus currículos, algumas disciplinas caracterizadas por seu enfoque interdisciplinar, nas quais a temática ambiental é abordada tanto nos aspectos biológicos quanto nos aspectos político-sociais, culturais e econômicos que a envolvem.

A predominância da abordagem de aspectos físico-naturais da questão ambiental na formação dos professores reflete-se diretamente na sua prática pedagógica. Na nossa pesquisa, verificamos que a maioria das atividades relatadas é voltada prioritariamente para os aspectos físico-naturais, discutindo-se muito pouco os aspectos políticos, econômicos, sociais e culturais. 0 trecho a seguir é um exemplo de resposta de um professor quando indagado sobre a forma de abordagem das questões ambientais no curso de graduação:

Não, puramente ecológicas. É aí que vem o problema da educação ambiental, nesse caso. Eu não tive acesso, na faculdade, a nada de 
educação ambiental. Eu tive ecologia pura e simples, bioma, cadeia alimentar, populações, vegetal etc. Só (PROFESSOR 11, 2004).

Contudo, consideramos também que os conhecimentos específicos de cada área são determinantes para o desenvolvimento de atividades de Educação Ambiental. Salientamos que aliar os conhecimentos específicos às implicações sociais, culturais, econômicas e políticas da temática ambiental pode gerar resultados muito mais ricos para uma educação que está tentando mudar suas concepções. D os 28 professores que responderam ao questionário, apenas 7 responderam que não tiveram disciplinas relacionadas à questão ambiental. Desses professores, um é formado em Matemática, um, em História, um, em Farmácia (leciona Biologia), um, em Q uímica, dois, em Biologia e um, em $\mathrm{G}$ eografia. É importante destacar que, dos professores que não tiveram acesso a disciplinas relacionadas a questões ambientais na graduação, um é formado em Química pela UFG. Constatamos que esse professor não teve a disciplina Química Ambiental, ao contrário do outro professor formado em Q uímica pela UFG, porque na época em que aquele cursou a graduação essa disciplina ainda não fazia parte da grade curricular do curso. D estacamos ainda que essa mesma disciplina incorporou, no novo Projeto Político Pedagógico, a Educação Ambiental, como resultado dos debates entre os professores sobre os problemas ambientais.

Com relação à questão que se reportava às fontes de informação para a realização das atividades relacionadas a essa temática, as mais citadas pelos professores foram a Internet, jornais ou revistas de circulação nacional, programas de televisão e livros. A figura 1 mostra a distribuição percentual de professores segundo as fontes de informação para a realização das atividades relacionadas à temática ambiental:

Os dados mostram que os professores têm interesse pela temática ambiental. Entretanto, é importante destacar que fontes como Internet e programas de televisão, dependendo da forma como são utilizadas, não são suficientes para a fundamentação teórica de um trabalho em Educação Ambiental. Essas fontes poderão ser ferramentas úteis, dependendo da forma como estão sendo assimiladas, elaboradas e reelaboradas por esses professores. 


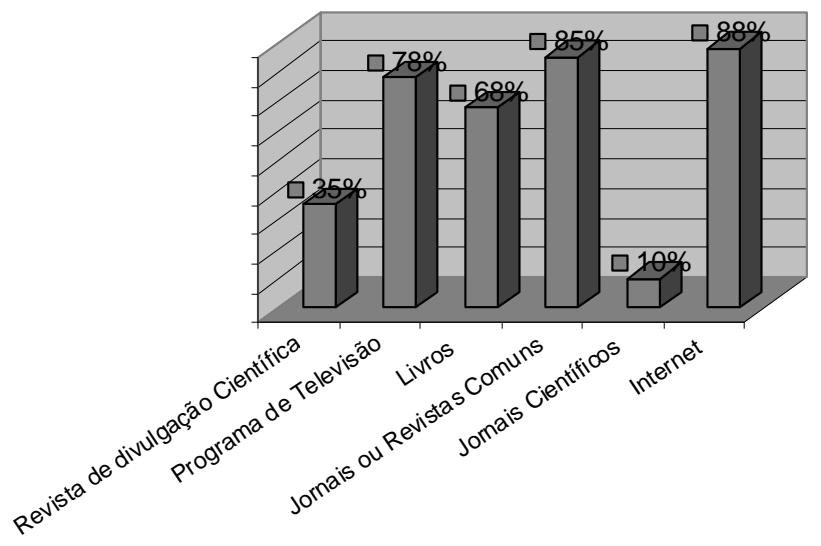

Figura 1 - Distribuição percentual de professores segundo as fontes de informação para as atividades sobre a temática ambiental.

Sobre essas fontes, Penteado (1994) destaca que é necessário mudar o modo de trabalhar com a informação. A autora afirma que:

As informações acumuladas culturalmente (contidas nos livros e computadores) passam a ser objeto de trabalho dos alunos que, orientados pelo professor, as analisam e discutem, tendo em vista apossarem-se delas de tal maneira que possam ser utilizadas como recursos ou instrumentos de compreensão da realidade e de resolução de seus problemas (PENTEAD 0, 1994, p. 57).

Assim, a Educação Ambiental, com a informação nessa dimensão, ultrapassa a mera acumulação de informações, visando transformar o conhecimento de senso comum, de cunho imediatista e não questionador, em um conhecimento mais elaborado, sistematizado e reflexivo.

Entre as respostas a essa questão, temos ainda que salientar que 3 professores utilizam jornais científicos para a realização de suas atividades, mostrando que buscam fontes que possam fornecer uma base teórica confiável para essa temática. Vale ressaltar que esses professores possuem uma formação diferenciada, visto que um é 
mestre, o outro está cursando mestrado e 0 último está cursando doutorado em Ciências Ambientais.

Também procuramos em nossa pesquisa conhecer as concepções dos professores sobre temas relacionados à problemática ambiental, porque entendemos que essas concepções podem influenciar o cotidiano pedagógico do professor.

$\mathrm{Na}$ questão que versava sobre a opinião dos professores a respeito da origem dos problemas ambientais, surgiram dois grupos de respostas que categorizamos como: "Modelo de desenvolvimento baseado no crescimento a qualquer custo" (21 professores - 75\%) e "Ação do homem frente à natureza" (3 professores - 11\%).

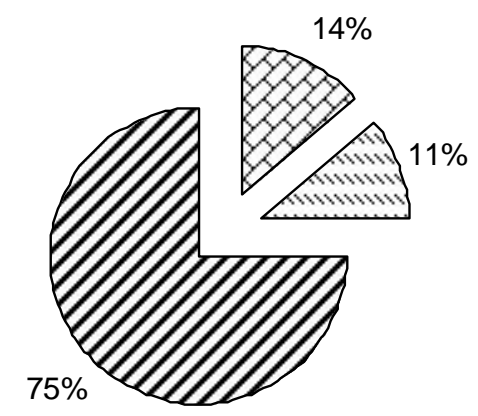

ఐ Não respondeu/Outros

๑ Ação do Homem

$\square$ Modelo de

Desenvolvimento

Figura 2 - O pinião dos professores sobre a origem dos problemas ambientais.

Entendemos que os dois grupos (Modelo de desenvolvimento baseado no crescimento a qualquer custo e Ação do homem frente à natureza) poderiam situar-se numa única categoria que significasse a ação do homem frente ao meio. Entretanto, foram diferenciados para demonstrar que uma grande porcentagem de professores (75\%) tem uma compreensão mais elaborada da relação ser humano-meio ambiente ao entendêla como resultado de um modelo econômico. A frase abaixo é exemplo da opinião predominante: 
A origem está relacionada a ação antrópica inadequada e exploratória, fruto dos efeitos do capitalismo (PROFESSOR 1, 2004).

Segundo Soffiati (2002), a crise ambiental da atualidade originase de uma concepção antropocêntrica, instrumentalizadora e utilitarista da natureza. Essa concepção tanto é o resultado complexo das relações capitalistas como também é responsável pela revolução tecnológica eclodida no final do século XVIII, na Inglaterra.

Grün (1996) destaca ainda que a crise ecológica, vista como um sintoma da crise da cultura ocidental, embora apresente múltiplas facetas, tem apontado quatro características que formaram os antecedentes históricos da Educação Ambiental:

O crescimento populacional exponencial; depleção da base de recursos naturais; sistemas produtivos que utilizam tecnologias poluentes e de baixa eficiência energética e sistemas de valores que propiciam a expansão ilimitada do consumo material (GRÜN, 1996, p. 21).

Diferentes abordagens são consideradas na discussão sobre a origem dos problemas ambientais, mas há um consenso de que a nossa civilização seria insustentável se todas as pessoas do planeta adotassem os padrões ecológicos do Norte (PORTO-GO NÇALVES, 2004a).

No que se refere às soluções apontadas pelos professores para os problemas ambientais, surgiram dois grupos de respostas que foram categorizados como: "Consaientização" - 25 professores (89\%) declararam que a solução é a conscientização, a mudança de valores e a reeducação - e "Fiscalização" - 6 professores (21\%) declararam que a solução está no cumprimento e criação de leis por parte dos órgãos públicos. Três professores (11\%) não responderam a essa questão. A afirmação abaixo é um exemplo das categorias:

As soluções estão no trabalho de conscientização e re-educação [sid ambiental nas escolas e universidades, bem como na criação de leis 
que possam punir os agressores ao meio ambiente, mas que sejam realmente cumpridas (PRO FESSOR 1, 2004).

Sobre a educação, Freire (1996) destaca que para 0 estabelecimento de uma prática educativa crítica que procure consaientizar os aprendizes é fundamental a convicção de que a mudança é possível. Não podemos estar no mundo, com o mundo e com os outros de forma neutra. Devemos nos inserir neste mundo e assim decidir, escolher e intervir na realidade. D essa forma, entendemos que ensinar na perspectiva da conscientização, como levantado pelos professores, exige que os educandos se transformem em reais sujeitos da construção e da reconstrução do saber ensinado, fazendo parte desse processo juntamente com o educador. Contudo, a construção e a reconstrução desse saber requerem do educador a compreensão de que ensinar exige dele atitudes que corroborem as suas palavras.

Pensando na educação escolar, buscamos saber a opinião dos professores sobre a potencialidade da escola na resolução dos problemas ambientais. Surgiram três grupos de respostas, que foram categorizados como: "Muito impatante" (14 professores - 50\%), "Impatante mas limitada" (11 professores - 39\%) e "Razoávd au fraca” (1 professor - 4\%). Dois professores (7\%) não responderam a essa questão. O u seja, a maioria dos professores reconhece a importância da escola na contribuição para a resolução dos problemas ambientais, salientando, em alguns casos, o seu papel de formação de um cidadão consciente.

Lima (2002) destaca que, em todo o histórico da recente crise ambiental, a educação tem sido lembrada como um instrumento capaz de responder positivamente a esses problemas, ao lado de outros meios, de ordem política, econômica, legal, ética, científica e técnica. D essa forma, consideramos a escola um dos meios de promover essa educação, e não o único meio. Entendemos que:

a Educação Ambiental é, por definição, apontada como portadora de processos individuais e coletivos que contribuem com: (1) a redefinição do ser humano como ser da natureza, sem que este perca 
o senso de identidade e pertencimento a uma espécie que possui especificidade histórica; (2) o estabelecimento, pela práxis, de uma ética que repense o sentido da vida e da existência humana; (3) a potencialização das ações que resultem em patamares distintos de consciência e de atuação política, buscando superar e romper com 0 capitalismo globalizado; (4) a reorganização das estruturas escolares e dos currículos em todos os níveis do ensino formal; e (5) a vinculação das ações educativas formais, não formais e informais em processos permanentes de aprendizagem, atuação e construção de conhecimentos adequados à compreensão do ambiente e problemas associados. Em síntese, uma práxis educativa que é sim cultural e informativa, mas fundamentalmente política, formativa e emancipadora, portanto, transformadora das relações sociais existentes (LOUREIRO, 2004, p. 31).

Essas ideias convergem para as apresentadas por autores como Paulo Freire, Moacir Gadotti, Rubem Alves, entre outros, e apontam para uma Educação Ambiental Crítica que objetiva promover ambientes educativos de mobilização voltados à intervenção sobre a realidade e seus problemas socioambientais.

Diante do fato de que a metade dos professores abordados na nossa pesquisa declara que a escola é muito importante na Educação Ambiental, consideramos essencial conhecer o que esses professores concebem ser Educação Ambiental.

Analisando as respostas, identificamos características de uma visão de Educação Ambiental crítica somente na fala de dois professores:

Para falar a verdade, eu nem sei se existe educação ambiental. É bastante provável que daqui a algum tempo a gente descubra que existe educação. E dentro do desenvolvimento educacional coerente e uma educação bem feita ela envolve inclusive a relação do indivíduo que está estudando com o ambiente [em] que ele se desenvolve. E ambiente significa 0 ambiente social, 0 ambiente urbano e também 0 ambiente natural. Então, eu acredito que educar ambientalmente é 
algo muito próximo de educar coerentemente. Então, eu acho que educar ambientalmente de maneira coerente é tentar desenvolver uma ética quanto à relação do homem com 0 meio ambiente (PROFESSOR 26, 2004).

Nas outras respostas, observamos dificuldades em definir Educação Ambiental, provavelmente originárias de uma formação pautada basicamente na abordagem dos aspectos físico-naturais dos problemas ambientais. Isso nos chamou a atenção, visto que o critério para a escolha dos professores a participar da pesquisa foi que estivessem desenvolvendo atividades relacionadas à questão ambiental, o que nos leva a inferir que a maioria das atividades ambientais relatadas foi trabalhada a partir do senso comum. Por isso, buscamos conhecer como eram essas atividades, por meio da solicitação de que os professores relatassem uma atividade de Educação Ambiental que estavam desenvolvendo naquele período ou que já tivessem desenvolvido.

A análise das respostas dos questionários mostrou claramente as diferenças entre práticas que se restringiam à sala de aula (leitura de jornais, exposição de fotos, vídeos, painéis) e práticas que se desenvolviam dentro e fora da sala de aula (gincanas, hortas, visitas a parques ecológicos e rios, feiras de ciências, entre outras), envolvendo os alunos diretamente com a realização de atividades na escola ou na comunidade. Por isso, estabelecemos duas categorias: atividads emdasse e atividades em dasse e extradasse A figura 3 mostra a distribuição percentual de professores segundo o tipo de atividade que realizam.

Com relação às atividades de Educação Ambiental realizadas em classe, dois professores disseram discuti-las durante a aula, quando relacionadas aos conteúdos ministrados.

Trabalho em grupo com interpretação de imagens (fotos, satélites, infográficos) enfocando aspectos do meio ambiente. São imagens boas, chocantes, que vão demandar imaginação, criatividade e raciocínio (PROFESSOR 4, 2004). 


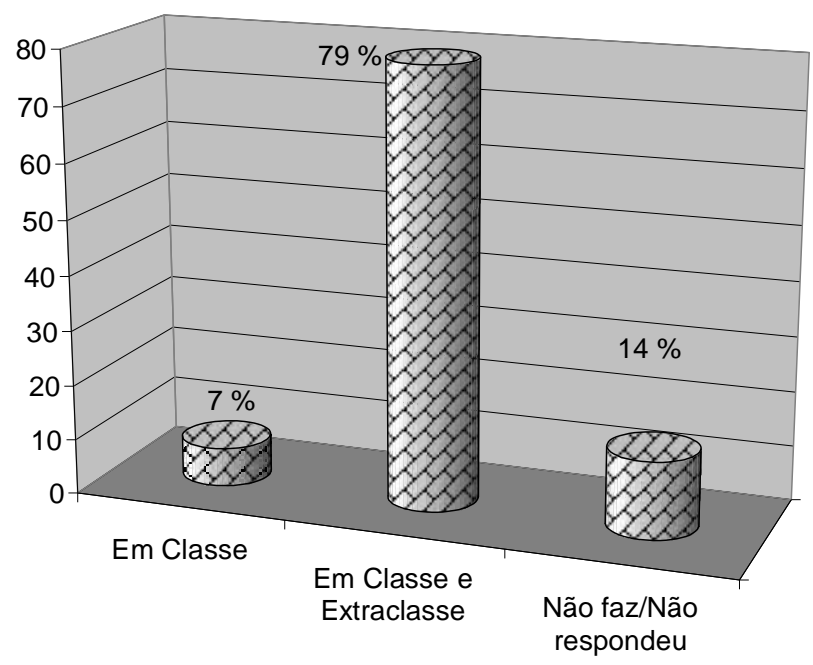

Figura 3 - Distribuição percentual de professores que desenvolvem atividades de educação ambiental, segundo o tipo de atividade.

Sobre as atividades de Educação Ambiental realizadas em classe e extraclasse, registramos um grande número de professores que dizem realizar tais atividades, 22 (79\%), o que nos leva a concluir que eles reconhecem que recursos didáticos mais criativos são mais adequados a uma perspectiva inovadora da Educação Ambiental. A seguir, alguns relatos desse tipo de atividade:

A gente elaborou o projeto, e nesse projeto a gente tentava trabalhar na prática algumas questões ambientais, para eles conhecerem um pouco mais a importância dos recursos que nós temos. E nós ficamos sabendo de uma reserva, de uma área de Aparecida de G oiânia, Serra das Areias. A extração de areia lá foi interrompida pelo governo. Então, a gente resolveu fazer uma visita [...]. Levamos todos os alunos lá na Serra das Areias. Aí lá a gente observou o ambiente já tocado pelo homem, trabalhado pelo homem. Os processos erosivos, onde já tinham [sid processos bem avançados. Depois, a gente foi para 0 ambiente, para o cerrado natural, que não tinha sido atingido pela ação do homem, para fazer uma comparação (PROFESSOR 28, 2004). 
Uma das nossas atividades foi o desenvolvimento de uma horta orgânica e a conscientização da importância da separação do material reciclável (PROFESSOR 18, 2004).

Projeto para avaliação da comunidade sobre o espaço (ambiente) Vaca Brava (um parque de Goiânia), questões ambientais como lixo, poluição, qualidade de vida [...] (PROFESSOR 10, 2004).

Analisando as falas dos professores, foi possível identificar que eles muitas vezes partem de problemas relacionados ao dia a dia, como lixo, reciclagem, coleta seletiva, para desenvolverem atividades de Educação Ambiental em suas aulas. As falas demonstraram também que eles reconhecem a importância de se discutir esse assunto na escola, que a partir desse tema podem ser desenvolvidas muitas ações em Educação Ambiental e que isso pode propiciar o envolvimento de alunos e professores para transformar a realidade da escola e até de suas casas.

Um aspecto das práticas dos professores que merece destaque é que, na sua maioria, essas práticas são feitas eventualmente, em datas comemorativas, eventos específicos. Pode-se dizer que não são trabalhos contínuos, fato que poderá não produzir os efeitos desejados para uma Educação Ambiental que mude valores:

Ano passado, a escola levou os alunos para visitar [...] (PROFESSOR 3, 2004).

Já realizei trabalhos de reciclagem [...] (PROFESSOR 13, 2004).

No primeiro semestre, desenvolvemos [...] (PROFESSOR 14, 2004).

Com relação ao desenvolvimento de um trabalho conjunto nas atividades de Educação Ambiental, a maioria, 21 (75\%), declarou que ocorre 0 envolvimento coletivo nas atividades de Educação Ambiental; apenas 7 professores (25\%) declararam que o trabalho conjunto não ocorre. A leitura dos questionários orientada à construção das 
categorias de análise mostrou claramente as diferenças na forma como o trabalho conjunto é desenvolvido. A maior parte declarou que esse envolvimento do grupo ocorre somente em atividades pontuais. Poucos professores disseram que 0 trabalho conjunto nas atividades de Educação Ambiental fazia parte do Projeto Político-Pedagógico da escola. Por isso, estabelecemos duas categorias: trabalhos pantuais e trabalhos vimulados aoprojeto da escla, e é possível afirmar que, em muitos casos, ocorre resistência por parte de alguns profissionais a trabalhar coletivamente as questões ambientais.

Nossos dados confirmam o que relata Vianna (2001) sobre como têm sido as práticas de Educação Ambiental. Ela comenta que essas práticas têm se restringido a projetos temáticos, desarticulados do currículo e das possibilidades de diálogo das áreas de conhecimento com 0 assunto. Muitas vezes, são campanhas isoladas ou ações efêmeras em datas comemorativas, iniciativas de um ou de alguns professores, que acabam por desenvolvê-las de forma extracurricular. São projetos descontextualizados e/ ou que se concentram em aspectos puramente ecológicos, deixando de lado os fatores culturais, políticos, econômicos e sociais que são parte integrante da temática ambiental.

Foi interessante observar que um professor, na sua fala, reconhece a complexidade conceitual quando se fala em interdisciplinaridade e multidisciplinaridade. Vale ressaltar que esse professor possui uma formação diferenciada, pois está na fase final do doutorado em Ciências Ambientais.

A tão sonhada interdisciplinaridade esbarra numa série de restrições. Poderiam ser enumeradas desde restrições pessoais até restrições institucionais. Entretanto, a multidisciplinaridade não, essa é fácil de ser colocada em prática. Então, já houve casos em que outros professores participaram eventualmente e ao participar meio que de maneira mais independente acabaram discutindo alguns conceitos. Mas não aquela coisa ideal de tentar acoplar esses conceitos de maneira interdisciplinar, de interpretar os conhecimentos das áreas correlatas e das áreas diferentes dentro de um plano comum, de uma coisa geral. 0 que também é uma coisa compreensível, porque é 
difícil de fazer. Isso requereria que eu como profissional da área biológica tivesse um aprofundamento num conhecimento na área humana, social. E, da mesma forma, o pessoal da área de humanas tivesse um conhecimento de biologia. E o caminho é esse, não tem como fugir (PROFESSOR 26, 2004).

Contudo, percebe-se, entre as diversas situações vividas e retratadas, que o fato de a maioria dos professores (75\%) realizar um trabalho conjunto, seja pontual ou no projeto da escola, pode significar que há uma consciência de que a resolução dos problemas ambientais exige 0 envolvimento de várias áreas do conhecimento.

Leff (2001) destaca que as estratégias epistemológicas para a articulação das ciências no campo ambiental e os processos inter e transdisciplinar de conhecimentos oferecem uma explicação mais concreta da crise ambiental gerada pela racionalidade econômica. As contribuições positivas desse processo transcientífico sobre a articulação dos processos materiais, que confluem para diversos processos socioambientais, abrem ao mesmo tempo possíveis transformações históricas para a construção de uma nova racionalidade produtiva orientada para um desenvolvimento sustentável e um manejo integrado de recursos.

\section{Considerações Finais}

Nosso estudo evidenciou que as atividades relacionadas à temática ambiental citadas pelos professores, em sua maioria, foram desenvolvidas de forma esporádica, em datas e eventos específicos, mostrando que não há uma continuidade no desenvolvimento dessas atividades e, portanto, elas dificilmente produzirão os efeitos desejados para uma Educação Ambiental crítica.

Sobre as práticas, constatamos, ainda, que esses professores compreendem que recursos didáticos criativos são mais adequados a uma perspectiva inovadora da Educação Ambiental, visto que a maioria das atividades citadas foi desenvolvida extraclasse. Por outro lado, as atividades extraclasse relatadas apontam uma predominância dos 
aspectos físicos em detrimento daqueles que a complexidade dos problemas ambientais demanda serem abordados, quais sejam: sociais, econômicos, culturais e políticos.

Nossa pesquisa mostrou que a educação oferecida nas escolas particulares não consegue apreender a complexidade das relações entre o ser humano e o meio ambiente. Assim, ressaltamos a necessidade de se criarem novos paradigmas que contemplem essa rede complexa de relações. Considerando que a Universidade é o local onde ocorre a formação inicial dos professores, é preciso refletir sobre o tipo de paradigma que essa instituição tem abraçado (LEFF, 2001). Dito de outra forma: é importante que se coloque a discussão sobre a formação de formadores, tema este negligenciado até nas normativas oficiais.

É importante também reformular as grades curriculares dos cursos de graduação que formam professores (Licenciaturas) de modo que contemplem a complexidade das relações entre ser humano e meio ambiente e promovam a formação continuada que possibilite a construção e reconstrução do educador ambiental.

Torna-se de igual importância o envolvimento da Universidade, bem como das escolas de ensino básico, em projetos que incluam a comunidade. Muitas vezes, o conhecimento produzido nos meios acadêmicos fica restrito aos mesmos, e a comunidade é excluída da discussão dos problemas ambientais com os quais convive diariamente. Enfim, o educador deve ter a consciência de seu inacabamento, ou seja, reconhecer que a sua reconstrução deve ocorrer diariamente.

\section{Referências}

AND RADE, Daniel Fonseca de. Implementação da Educação Ambiental em Escolas: uma reflexão. Reista detrônica dbMestradoemEduraçãoAmbiental, Rio G rande, v. 4, p. 15, out./ dez. 2000.

BAÍA JÚNIOR, Pedro Chaves; GUIMARÃES, Diva Anélie de Araújo. Educação Ambiental nos cursos de licenciatura em ciências biológicas de algumas universidades federais brasileiras - 0 caso da UFPA. In: ENCONTRO DE PESQUISA EM EDUCAÇÃO AMBIENTAL, 2., 2003, São Carlos. Universidade Federal de São Carlos. CD-ROM 
BARRETO, Andréa Cristina G. Paes; GUIMARÃES, Diva Anélie de Araújo; SILVA, Marilena Loureiro da. Educação ambiental e representação social: saberes e imagens da prática acadêmica do curso de pedagogia. In: ENCONTRO DE PESQUISA EM EDUCAÇÃO AMBIENTAL, 2., 2003, São Carlos. Universidade Federal de São Carlos. CD-ROM.

BRASIL. Parâm ros Cumiailares Nacionais Brasilia: Ministério da Educação; Secretaria de Educação Fundamental, 1997.

. Pdítica Naaianal deEduracãa Ambiental. Lei no 9795/ 99. Brasilia: Ministénio da Educação, 1999.

COSTA, Gislaine Gomes da; FREITAS, Denise de. Análise do grau de ambientalização curricular no curso de licenciatura em pedagogia da Universidade Federal de São Carlos. In: ENCONTRO DE PESQUISA EM EDUCAÇÃO AMBIENTAL, 2., 2003, São Carlos. Universidade Federal de São Carlos. CD-ROM.

DIAS, Genebaldo Freire. EducacãoAnbiettal - Princípios e práticas. 4. ed. São Paulo: Gaia, 1994. p. 58.

ECHEVERRÍA, Agustina Rosa; BENITE, Anna M. Canavarro; SOARES, Márlon Herbert F. B. A pesquisa na formação inidal de professores de química - a experiência do Instituto de Química da Universidade Federal de Goiás. Trabalho apresentado no Workshop da Sociedade Brasileira de Química na 30a Reunião Anual. Águas de Lindóia - SP, 2007. http:/ / www.sbq.org.br/ 30ra/ wordensino.php

GRÜN, Mauro. Ética eEdurasão Anbietal: a conexão necessária. 5. ed. São Paulo: Papirus, 1996.

INSTITUTO BRASILEIRO DE GEOGRAFIA E ESTATÍSTICA. SensoEduradinal. 2001.

LEFF, Enrique. EpistemogaAAnkiental. São Paulo: Cortez, 2001. 240 p.

LIMA, Gustavo Ferreira da Costa. Crise ambiental, educação e cidadania: os desafios da sustentabilidade emancipatória. In: CASTRO, Ronaldo Souza; LAYRARGUES, Philippe Pomier; LOUREIRO, Carlos Frederico B. (O rg.). Educação Ambiental: repensando o espaço da cidadania. 2. ed. São Paulo: Cortez, 2002. p. 109-141.

LOUREIRO, Carlos Frederico B. Educação Ambiental e movimentos sociais na construção da cidadania ecológica e planetária. In: CASTRO Ronaldo Souza; LAYRARGUES, Philippe Pomier; LO UREIRO, Carlos Frederico B. (O rg.). Eduragão Ambiental: repensando o espaço da cidadania. 2. ed. São Paulo: Cortez, 2002. p. 69-98.

. TrajecóiaseFundamentos daEduraçãoAnhietal. São Paulo: Cortez, 2004. p. 31.

LÜDKE, Menga; ANDRÉ, Marli E. Dalmazo Afonso de. Pesquisa em Eduraçãa abordagens qualitativas. São Paulo: EPU, 1986.

MELO, Rosemeri Santos de. A dimensão ambiental da educação e as redes de informação e conhecimento. Rexista Elerônica do Mestradb em Eduração Ambiental, Rio Grande, v. 05, p. 07-17, jan./ fev./ mar. 2001. 
PENTEADO , Heloísa D upas. Méo ambieteefomação deprofessores São Paulo: Cortez, 1994. 120 p. (Coleção Q uestões de Nossa Época).

PORTO-GO NÇALVES, Carlos Walter. O desafioAmbiental. Os porquês da desordem mundial. Rio de Janeiro: Record, 2004a. . Os(des)caminhosdbmioambiente 11. ed. São Paulo: Contexto, 2004b.

QUINTAS, José Silva. Educação no processo de gestão ambiental: uma proposta de educação ambiental transformadora e emancipatória. In: LAYRARGUES, Philippe Pomier (Coord.). Idatidades da Edurasão Ambiental Brasilera Brasília: Ministéno do Meio Ambiente; Diretoria de E ducação Ambiental, 2004. p. 113-140.

REIGOTA, Marcos Antonio dos Santos. Ciência e sustentabilidade: a contribuição da educação ambiental. Rexista deA valiação da Edureşão Superia, São Paulo, v. 12, n. 2, p. 219-232, jun. 2007.

SACHS, Ignacy. Caminhos para o desenvdvimeto sustetávd. Rio de Janeiro: Garamond, 2002.

SOFFIATI, Arthur. Fundamentos filosóficos e históricos para 0 exercício da ecocidadania e da ecoeducação. In: CASTRO, Ronaldo Souza; LAYRARGUES, Philippe Pomier; LOUREIRO, Carlos Frederico B. (Org.). Eduracão Ambiettal: repensando o espaço da cidadania. 2. ed. São Paulo: Cortez, 2002. p. 23-68.

STERLING, Stephen. Sustainable eduration: re-visioning learning and change. Bristol, UK: Green Books, 2001.

VELASCO, Sirio Lopez. Algumas reflexões sobre a PNEA [Política Nacional de Educação Ambiental, lei no 9795 de 27/ 04/ 1999]. Reista Elerônica do Mestrado em EducaçãoAmbietal, Rio G rande, v. 8, p. 12-20, jan./ jun. 2002.

VIANNA, Lucila Pinsard. Meio ambiente na escola: a proposta do MEC. Pátio São Paulo, n. 19, p. 26-29, nov./ dez. 2001.

Artigo: recebido em 14/ 08/ 2008 - aprovado em 17/ 12/ 2008 